\title{
A triple band modified F-shaped monopole antenna for RFID application
}

\author{
Spoorti Barigidad ${ }^{1}$, Aishwarya C. Yeshawant ${ }^{2}$, Sridevi Rao ${ }^{3}$, Tharunya C. $\mathrm{A}^{4}$, \\ Tanweer $\mathrm{Ali}^{5}$, Sameena Pathan ${ }^{6}$ \\ 1,2,3,4,5 Department of Electronics \& Communication Engineering, Manipal Institute of Technology, \\ Manipal Academy of Higher Education, India \\ ${ }^{6}$ Department of Computer Science and Engineering, Manipal Institute of Technology, \\ Manipal Academy of Higher Education, India
}

\begin{tabular}{l} 
Article Info \\
\hline Article history: \\
Received Apr 3, 2020 \\
Revised May 31, 2020 \\
Accepted Jun 14, 2020 \\
\hline
\end{tabular}

Keywords:

Dual band

Monopole

Rectangular stub

RFID

Surface current

\begin{abstract}
Radio frequency identification (RFID) is a very prominent technology and is used in object-attached identification and tracking tags. In this paper a triple band monopole antenna is designed to work at 2.2-2.6 GHz (lower RFID band), 5.3-6.8 GHz and 8.7-9.5 GHz (upper RFID band) frequency ranges. The antenna design resembles a modified F-shaped radiator and is built on a low cost easily available FR4 dielectric substrate. Initially an F-shaped radiator with partial ground plane is studied which exhibits the operation at 2.6 and $6.5 \mathrm{GHz}$. Further, modifying this F-shaped radiator exhibits an additional resonance at $9.2 \mathrm{GHz}$. Fundamental characteristics such as reflection coefficient $\left(S_{11}\right)$, radiation pattern and 3D gain have been analyzed and good results have been obtained. Parametric analysis is carried out to fix the optimized antenna dimensions. All the simulations are carried out using the high frequency structure simulator software (HFSS). The antenna structure is easy to design and produce, and ideal for use in RFID applications.document quickly and accurately, to determine its relevance to their interests, and thus to decide whether to read the document in its entirety.
\end{abstract}

This is an open access article under the CC BY-SA license.

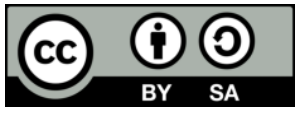

\section{Corresponding Author:}

Tanweer Ali,

Deptartment of Electronics \& Communication Engineering,

Manipal Institute of Technology,

Manipal Academy of Higher Education,

Tiger Circle Road, Madhav Nagar, Manipal, Karnataka 576104, India.

Email: tanweer.ali@manipal.edu

\section{INTRODUCTION}

Now a days the use of compact and multiband antenna is very much required for diverse wireless applications [1-4]. Radio frequency identification (RFID) is the latest technology used to track objects using Radio frequency signals and to distinguish moving automobiles. The antenna should be light weight, architecturally simple to fabricate with minimal cost. RFID is used between the reader and the movable object. It is used to identify, categorize and track. The RFID antenna is used to convert electrical field current into EM waves, and then emit it into space, which can then be obtained by a tag antenna and transferred as electrical energy. For RFID, a simple microstrip fed monopole antenna is provided. Printed monopole antennas are prefered because of their simplistic structures and compact size and are optimal for dual band and multiband systems. It is best suited for achieving large bandwidth and omnidirectional radiation pattern. Compact printed monopole antennas are used in RFID. Various antennas have been designed for 
865-869 MHz UHF band, and the basic structure is written in the form of spiral. Low frequency bands, high frequency bands, ultra high frequency bands $(2.4,2.48$ and $5.8 \mathrm{GHz})$ are most favored among these UHF bands for RFID application [5].

RFID systems operate at a frequency range of $125 \mathrm{KHz}$ to $13.65 \mathrm{MHz}$ for information transmission. Chang et al. [6] proposed a lightweight dual-mode single feed antenna for successful radio frequency recognition. Panda et al. [7] proposed a dual band monopole anteena supporting, 2.41 and $5.85 \mathrm{GHz}$ frequencies using a $\mathrm{C}$ shaped structure, and further proposed a $\mathrm{U}$-shaped dual monopole antenna supporting dual frequencies of 1.84 and $5.82 \mathrm{GHz}$ [8]. The antenna suggested in [9] is easy and lightweight in size, with a matching broadband impedance, clear radiation pattern and correct RFID frequency gain attributes. The new type of RFID reader tri-band antenna is introduced. The benefits of using lower frequencies is due to the low cost, however these models have short read ranges with lower data transfer speeds [10]. Yang et al. [11] proposed a circularly polarized patch antenna that integrates attractive qualities such as broad impedance and AR bandwidth, large gain, simple design, production and integration. In [12], various resonating lengths are introduced for a monopole strip antenna to obtain dual band operation. The antenna's two resonant forms are combined with various lengths of the monopolies, where a longer arm adds value to the lower resonance frequency and a lighter arm for larger resonance frequency. A coplanar waveguide fed patch antenna with average gain $>4.1 \mathrm{dBi}$ for RFID applications is proposed in [13].

The radiation process of an antenna was evaluated on the basis of numerical method. Chen et al. [14] proposed caopacitive folded CPW fed slot antenna with a gain of $4.2 \mathrm{~dB}$. The H-plane radiation patterns are nearly omnidirectional, this property and its compact uniplanar shape allow the transmitters suitable for use as RFID tags. A CPW fed F-shaped antenna with folded rectangiular slots on a thin substrate is proposed by Liu et al. [15]. To broaden the resistance range and miniaturize, the antenna is scaled for acceptable use in $5.8-\mathrm{GHz}$ radio frequency identification systems, a branch of the $\mathrm{F}$ structured antenna is shorted. A $38 \times 30 \times 1.6 \mathrm{~mm}^{3}$ dual band monopole antenna was proposed by Pandey et al. [16], the antenna provides equivalent broadband impedance, and acceptable gain features greater than $2.5 \mathrm{dBi}$ and reliable patterns of omnidirectional radiation in the RFID and WLAN frequency areas. Singh et al. [17] proposed a circular strip microstrip patch antenna by connecting a strip which is reverse to the microstrip feed line to the radiating corners, this alters the current allocation and radiation on both the transmitter and receiver at the 2nd resonant frequency. A slotted circular monopole antenna with spike shaped slots is proposed in [18], the antenna's design consists of the sockets which are in a circular shape, where the square is removed and then scaled around each other. Cheng et al [19], proposed a CPW fed monopole antenna for dual band operation using strip sleeves, with operation bandwidth range between $900-1800 \mathrm{MHz}$.

A single band patch antenna operating at $5.4 \mathrm{GHz}$ is presented in [20], monopole antennas are an attractive choice and are representative for wearable electronics because of their low-profile properties, compatible with planning and non-planar surfaces. Printed rectangular monopole antenna proposed in [21] have been observed to be small in size and simple in design and manufacture, but their performance is very good for multiband applications. The L-shaped monopole antenna presented in [22] is designed by modifying the ground surface by placing a non-symmetrical horizontal L-slot. A multiband monopole antenna covering three bands is prented in [23] the radiating antenna patch is fed via rail line, and the model has radiation pattern of omnidirectional and the gain is stable. Similarly, a monopole antenna operating at 2.3 and $4.9 \mathrm{GHz}$ is proposed in [24]. Thus, monopole antennas are an attractive choice due to small size and ability to blend with the surrounding. These design principles have led antenna designers to explore a large range of antenna configurations to meet the conflicting needs of various wireless devices.

In this paper a monopole antenna is proposed for upper band RFID applications. The antenna has a compact dimension of $40 \times 28 \times 1.6 \mathrm{~mm}^{3}$ and shows triple band of operation. The band at 2.3 has a bandwidth of $400 \mathrm{MHz}$, at $6.2 \mathrm{GHz}$ it has a bandwidth of $1500 \mathrm{MHz}$ and band at $9.2 \mathrm{GHz}$ has a bandwidth of $1800 \mathrm{MHz}$. The antenna consists of a modified F-shaped radiator, partial ground plane and is fed by microstrip line using lumped port excitation to achieve and impedance matching of 50 ohms. All the necessary simulations are carried out using high frequency structure simulator software (HFSS).

\section{ANTENNA DESIGN AND CONFIGURATION}

The overall design of the presented antenna is depicted in Figure 1. The antenna is inspired by the design presented in [25]. Antenna is constructed on a dielectric material FR4 which has a relative permittivity of 4.4, loss tangent of 0.02 and height of $1.6 \mathrm{~mm}$. The FR4 substrate is chosen because it is a low cost and readily available dielectric material relative to other materials and it also provides more flexibility in design. The microstrip feed-line is $3 \mathrm{~mm}$ wide (w1) and $34 \mathrm{~mm}$ long (L2). The ground plane is $\mathrm{L} 1 \mathrm{~g}=17 \mathrm{~mm}$ long and $\mathrm{W} 1 \mathrm{~g}=28 \mathrm{~mm}$ wide. The antenna has a modified F-shaped radiator and partial ground plane. It is fed by lumped port excitation to achieve an impedance matching of $50 \mathrm{ohms}$. No external impedance matching 
circuit is required by the antenna as the placement of the modified F-shaped radiator and partial ground plane helps in achieving good impedance bandwidth over the triple band of operation. The fixed dimension values $(\mathrm{mm})$ for an antenna configuration are: $-\mathrm{W} 1=\mathrm{W} 1 \mathrm{~g}=28, \mathrm{~L} 1=40, \mathrm{~L} 2=34, \mathrm{~d} 2=20, \mathrm{a} 2=7.5, \mathrm{c} 1=1.5, \mathrm{c} 2=8, \mathrm{~b} 2=3$, b1 $=4, w 1=3,13=20, \mathrm{~L} 1 \mathrm{~g}=17$.

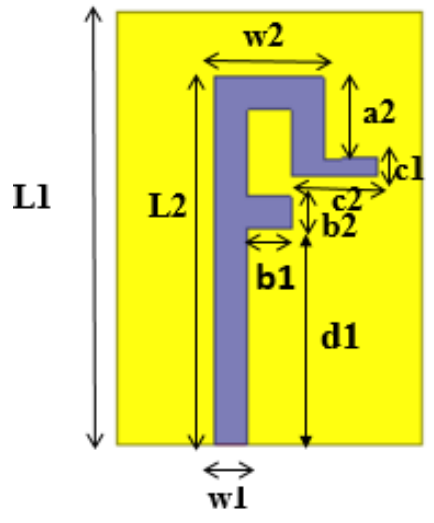

(a)

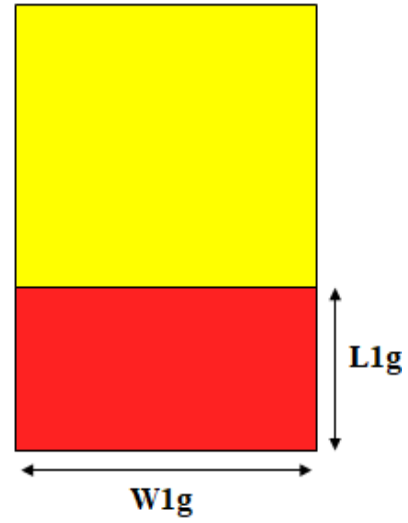

(b)

Figure 1. Proposed configuration, (a) Radiating part, (b) Ground part

\subsection{Evolution stages of the proposed antenna}

Originally, the antenna configuration is achieved using a rectangular stub (i.e. Antenna 1) having length of L2 and a width of w1 with full ground plane as illustrated in Figure 2. The reflection coefficient $\left(S_{11}\right)$ of this antenna is depicted in Figure 3, wherein it can be studied that this antenna does not exhibit any useful operating band. The next antenna stage (Antenna 2) is conceived with symmetric feed line with T-shaped stub and the ground plane is reduced to the length of $\mathrm{L} 1 \mathrm{~g}$, and width of $\mathrm{W} 1 \mathrm{~g}$ as illustrated in Figure 2. The $S_{11}$ result of this antenna is depicted in Figure 3, wherein again it can be observed that antenna does not exhibit any useful resonance. In the next stage (Antenna 3) a rectangular stub is added having length of w2 and is palced horizontally to the tip of Antenna 2 to form an intermediate $\mathrm{F}$ shape, while keeping the ground plane constant as depicted in Figure 2. As a result of this configuration dual band operation at 2.5 and $6.5 \mathrm{GHz}$ is achieved which is due to the change in current path, as depicted in Figure 3.
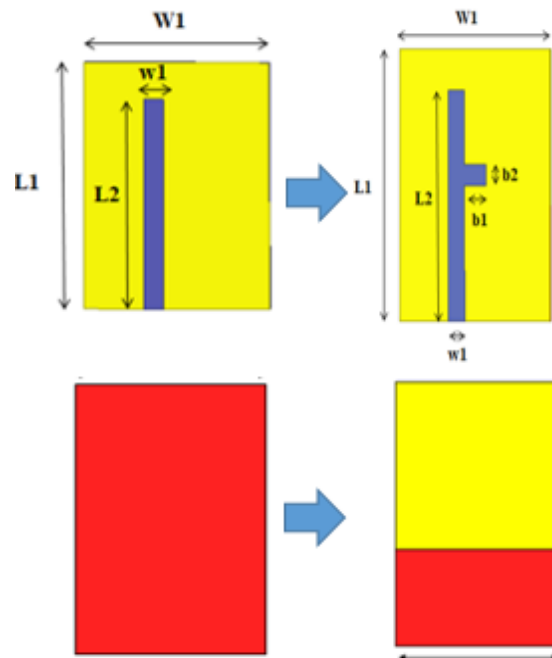

Antenna 1
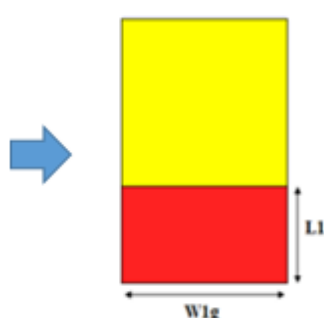

Antenna 2
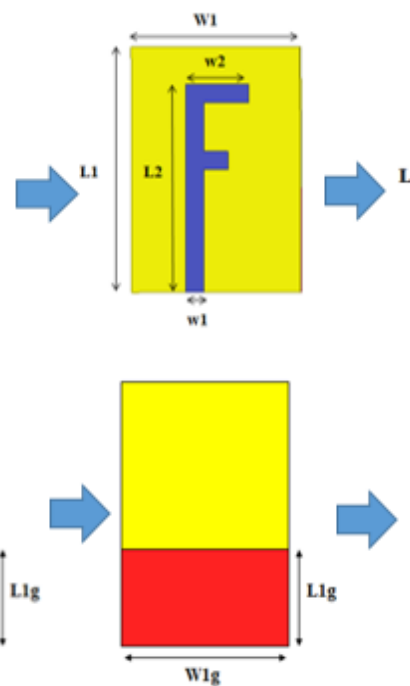

Antenna 3
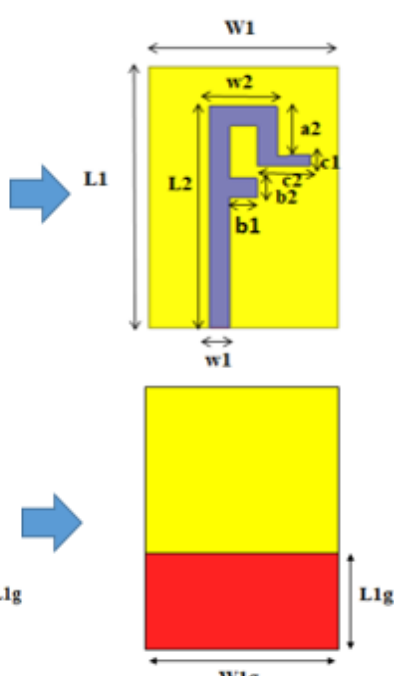

Proposed

Antenna

Figure 2. Evolution stage of the proposed configuration 
Furthermore, to achieve additional band of operation the F shaped antenna is modified by adding two rectangular stub as illustrated in Figure 2. This configuration forms the proposed antenna dsign as it can be seen that due to the modification of F-shaped radiator the surface current distribution further changes which in turn increases the total current length path, thus, making the proposed configuration to operate at 2.3 $, 6.2,9.2 \mathrm{GHz}$ (triple band) as detailed in Figure 3. There is a slight change in the operation of first two band (i.e. $2.5 \mathrm{GHz}$ now operates at 2.3 and $6.5 \mathrm{GHz}$ now operates at $6.2 \mathrm{GHz}$ ) achieved by Antenna 3 which is mainly due to the change wavelength due to the modification of F-shaped structure.

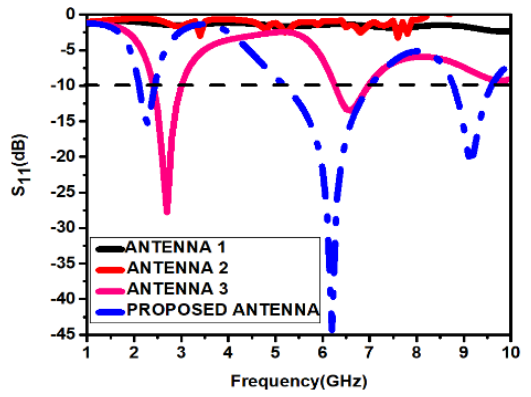

Figure 3. The $S_{11}$ for the structures shown in evolution stages

\section{PARAMETRIC STUDY}

To describe the effect of varying patch and ground lengths on the performance of the antenna parametric analysis is performed. The efficiency of the design is influenced by b2, c2 and L1g, hence the study is computed for these parameters and the results are shown in Figure 4.

\subsection{Effect of rectangular stub length}

The effect of rectangular stub b2, c2 is observed on impedance matching of the antennas. This study is computed by varying the width of rectangular stub b2 and length of rectangular stub $\mathrm{c} 2$ and the variation in terms of $S_{11}$ is observed which is depicted in Figures 4 (a) and (b). It can be studied that length and width has significant effect on second resonant frequency $(6.2 \mathrm{GHz})$ compared to first resonant frequency $(2.3 \mathrm{GHz})$ and third frequency $(9.2 \mathrm{GHz})$.

\subsection{Effect of length of ground plane}

The effect of ground plane length $(\mathrm{L} 1 \mathrm{~g})$ on impedance matching is shown in Figure 4(c). From the $\mathrm{S}_{11} \mathrm{plot}$ it can be observed that the best $S_{11}$ matching is observed at $\operatorname{Lg} 1=17 \mathrm{~mm}$.

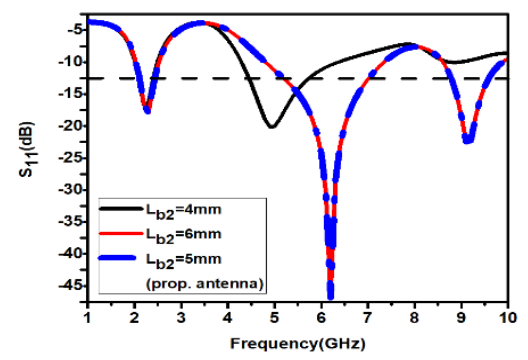

(a)

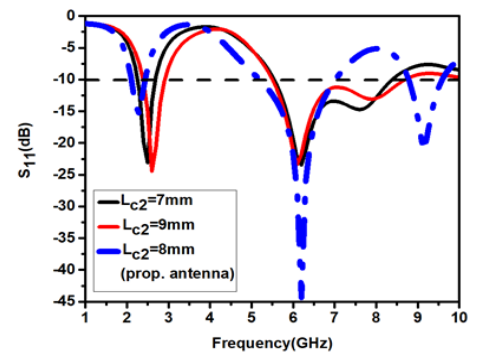

(b)

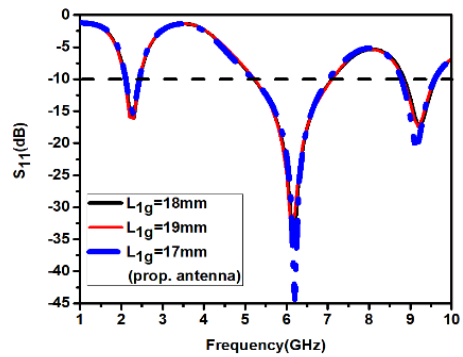

(c)

Figure 4. Return loss results for different values of, (a) b2, (b) c2, (c) L1g

\section{RESULTS AND DISCUSSION}

A triple band properties for RFID applications are achieved using the built antenna.This can be done by altering the pattern of radiation in the antenna configuration being proposed. The simulated $S_{11}$ result of the antenna is depicted in Figure 5. The antenna exhibits triple band of operation at 2.2-2.6 GHz (lower RFID 
band, bandwidth $1600 \mathrm{MHz}$ ), 5.3-6.8 GHz and 8.7-9.5 GHz (upper RFID band, bandwidth of 600 and $800 \mathrm{MHz}$ respectively) frequency ranges. The obtained bandwidth is optimum to be used for RFID applications. The actual surface current densities of the radiating patch and the ground plane of the proposed antenna are measured to consider the principle of triple band characteristics. This is illustrated below in Figure 6. Figures 6 (a),(b) and (c) shows the surface current densities for front and ground plane, which shows that the direction of currents is changing at the edges for $2.3 \mathrm{GHz}, 6.2 \mathrm{GHz}$ and $9.2 \mathrm{GHz}$. Also it can be observed that the ground plane current is flowing in opposite direction.

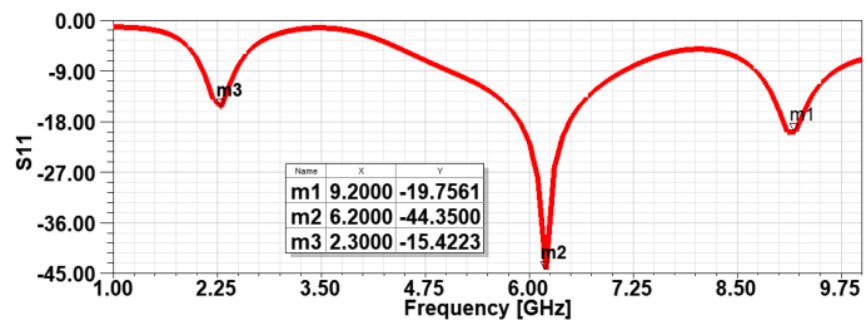

Figure 5. The simuated $S_{11}$ result for the proposed structure

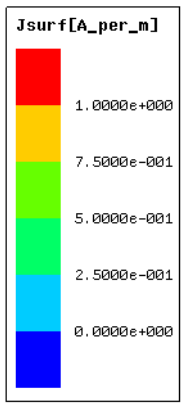

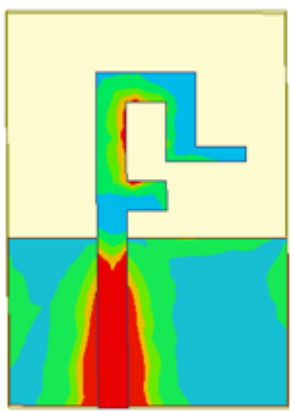

(a)

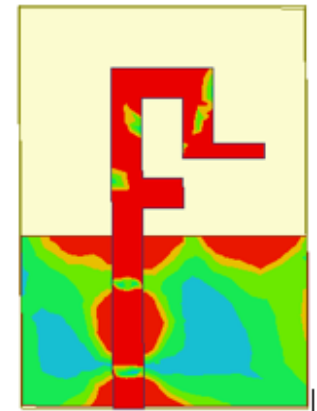

(b)

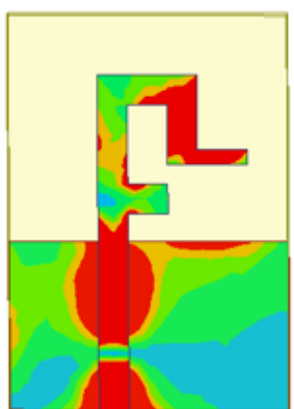

(c)

Figure 6. Current distributions at, (a) $2.3 \mathrm{GHz}$, (b) $6.2 \mathrm{GHz}$, (c) $9.2 \mathrm{GHz}$

The recorded 2D-polar radiation profiles of the proposed configuration at 2.3, 6.2 and $9.2 \mathrm{GHz}$ is illustrated in Figure 7. The antenna gives eight shaped radiation pattern in E-palne and zero shaped pattern in H-plane. The cumulative 3D gain pattern for the antenna being proposed is depicted in Figure 8 . The final proposed design has a gain of around $1.45,3.53$ and $4.98 \mathrm{~dB}$ at the operating frequency of 2.3, 6.2 and $9.2 \mathrm{GHz}$, repectively. The obtained gain can easily meet the requirmrnt of RFID applications. A comparative analysis of the proposed antenna with similar types in literature is compared and detailed in Table 1. It is evident from the table that the RFID antenna proposed in this paper has several advantages over its counterparts.

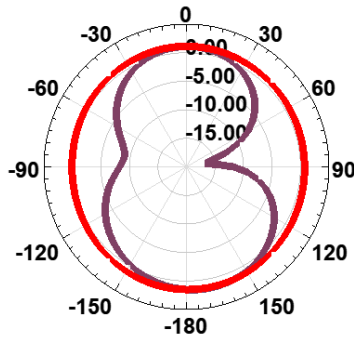

(a)

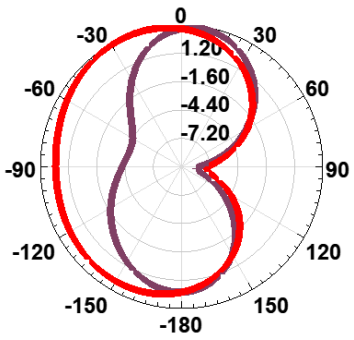

(b)

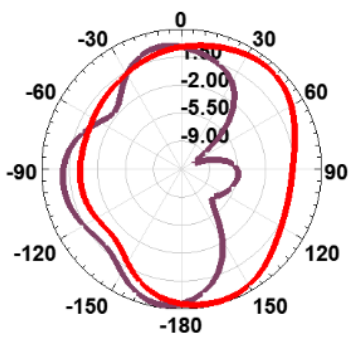

(c)

Figure 7. 2D polar radiation pattern modeled and calculated for, (a) $2.3 \mathrm{GHz}$, (b) $6.2 \mathrm{GHz}$, (c) $9.2 \mathrm{GHz}$ (red color: H-plane and violet color: E-plane) 


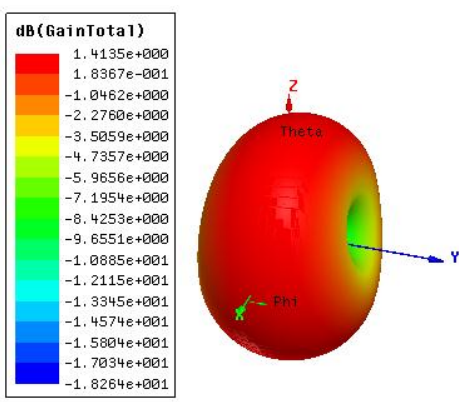

(a)

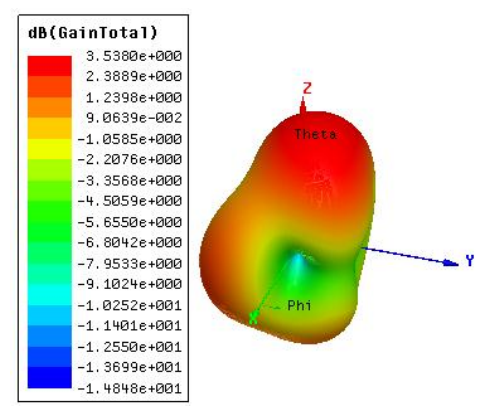

(b)

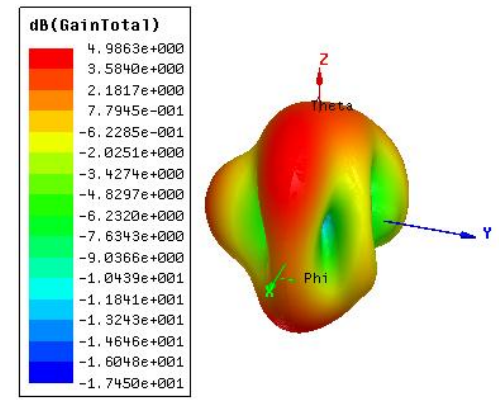

(c)

Figure 8. Gain for, (a) $2.2 \mathrm{GHz}$, (b) $6.2 \mathrm{GHz}$, (c) $9.2 \mathrm{GHz}$

Table 1. Comparison with similar RFID monopole antenna

\begin{tabular}{ccccc}
\hline Ref. & Antenna type & Gain $[\mathrm{dB}]$ & Bandwidth $[\mathrm{MHz}]$ & Size $\left[\mathrm{mm}^{2}\right]$ \\
\hline$[6]$ & Slotted Patch & 2.16 and 2.54 & 390 & $60 \times 50.3$ \\
{$[7]$} & Patch Antenna & 1.71 and 2.67 & 400 & $80 \times 45$ \\
{$[8]$} & U shaped & 2.98 & 840 & $30 \times 30$ \\
{$[11]$} & Circular patch antenna & 2.0 and 2.6 & 4700 & $32 \times 32$ \\
{$[15]$} & F shaped & 4 & 640 & $16.5 \times 20$ \\
Proposed Antenna & Modified F shaped & $1.45,3.53,4.98$ & $400,1500,1800$ & $40 \times 28$ \\
\hline
\end{tabular}

\section{CONCLUSION}

In this paper antenna to be utilized for RFID technologies is suggested. The proposed configuration covers both upper and lower RFID band applications and operate at three distinict frequency band from 2.2-2.6 GHz centered at $2.3 \mathrm{GHz}, 5.3-6.8 \mathrm{GHz}$ centered at $6.2 \mathrm{GHz}$, and 8.7-9.5 GHz centered at 9.2 $\mathrm{GHz}$. Parametric investigations are carried out to judge the effect of important parameters on antenna performance. It is studied from the analysis that ground plane and rectangular stub which forms the modified F-shape radiator has considerable affect on the impedance matching of the antenna. The antenna has the advantage of high bandwidth, ease of design, triple band of operation, high gain and stable radiation pattern thus, making the proposed design a competitive candidate for the aforesaid application.

\section{REFERENCES}

[1] T. Ali, M. S. Aw and R. C. Biradar Ali, "A Compact Bandwidth Enhanced Antenna Loaded with SRR For WLAN/WiMAX/Satellite Applications," Advanced Electromagnetics, vol. 7, no. 4, pp.78-84, 2018.

[2] N. Fathima, K. S. Nayana, T. Ali and R. C. Biradar, "A miniaturized slotted ground fractal Koch multiband antenna for wireless applications," 2017 2nd IEEE International Conference on Recent Trends in Electronics, Information \& Communication Technology (RTEICT), Bangalore, pp. 251-255, 2017.

[3] T. Ali, K. D. Prasad and R. C. Biradar, "A miniaturized slotted multiband antenna for wireless applications," Journal of Computational Electronics, vol. 17, no. 3, pp.1056-1070, 2018.

[4] S. A. W. Mohammad, M. M. Khaleeq, T. Ali and R. C. Biradar, "A miniaturized truncated ground plane concentric ring shaped UWB antenna for wireless applications," 2017 2nd IEEE International Conference on Recent Trends in Electronics, Information \& Communication Technology (RTEICT), Bangalore, pp. 116-120, 2017.

[5] K. Siakavara, S. Goudos, A. Theopoulos, J. Sahalos, "Passive UHF RFID Tags with Specific Printed Antennas for Dielectric and Metallic Objects Applications. Radioengineering, vol. 26, no. 3, pp. 735-745, 2017.

[6] L. Chang, H. Wang, Z. Zhang, Y. Li and Z. Feng, "Compact Single-Feed Dual-Mode Antenna for Active RFID Tag Application," in IEEE Transactions on Antennas and Propagation, vol. 63, no. 11, pp. 5190-5194, 2015.

[7] S. K. Mishra, R. K. Gupta, A. R. Vaidya and J. Mukherjee, "Printed Fork Shaped Dual Band Monopole Antenna for Bluetooth and UWB Applications with $5.5 \mathrm{GHz}$ WLAN Band Notched Characteristics," Progress In Electromagnetics Research C, vol. 22, pp. 195-210, 2011.

[8] J. R. Panda and R. S. Kshetrimayum, "A compact printed U-shaped dual-band monopole antenna for wireless and RFID applications," 2009 Applied Electromagnetics Conference (AEMC), Kolkata, pp. 1-4, 2009.

[9] J. R. Panda and R. S. Kshetrimayum, "A Printed 2.4 GHz /5.8 GHz Dual-Band Monopole Antenna with a Protruding Stub in the Ground Plane for WLAN and RFID Applications," Progress In Electromagnetics Research, vol. 117, pp. 425-434, 2011.

[10] Bo Wang and Wenqing Wang, "A miniature tri-band RFID reader antenna with high gain for portable devices," International Journal of Microwave and Wireless Technologies, vol 9, no. 5, pp. 1163-1167, 2017. 
[11] W. Yang, J. Zhou, Z. Yu and L. Li, "Single-Fed Low Profile Broadband Circularly Polarized Stacked Patch Antenna," in IEEE Transactions on Antennas and Propagation, vol. 62, no. 10, pp. 5406-5410, 2014.

[12] M. N. Suma, R. K. Raj, M. Joseph, P. C. Bybi and P. Mohanan, "A compact dual band planar branched monopole antenna for DCS/2.4-GHz WLAN applications," in IEEE Microwave and Wireless Components Letters, vol. 16, no. 5, pp. 275-277, 2006.

[13] Wen- Chung Liu, "A coplanar waveguide- fed folded- slot monopole antenna for $5.8 \mathrm{GHz}$ radio frequency identification application," Microwave and optical technology letters, vol. 49, no. 1, pp. 71-74, 2007.

[14] S-Chen and P. Hsu, "CPW-fed folded-slot antenna for 5.8 GHz RFID tags," in Electronics Letters, vol. 40, no. 24, pp. 1516-1517, 2004.

[15] Wen- Chung Liu and Chao- Ming Wu, "CPW- FED shorted F- shaped monopole antenna for 5.8- GHz RFID application," Microwave and optical technology letters, vol. 48, no. 3, pp. 573-575, 2006.

[16] A. Pandey and R. Mishra, "Compact Dual Band Monopole Antenna for RFID and WLAN Applications," Materials Today: Proceedings, vo. 5, no. 1, pp. 403-407, 2018.

[17] A. Batta and Er. Ruchi, "A Compact Microstrip Patch Antenna for RFID and WLAN Applications," International Research Journal of Engineering and Technology, vol. 3, no. 4, pp. 1212-1215, 2016.

[18] G. M. Dandime and V. G. Kasabegoudar, "A slotted circular monopole antenna for wireless applications," International Journal of Wireless Communications and Mobile Computing, vol. 2, no. 2, pp. 30-34, 2014.

[19] C. H. Cheng, W. J. Lv, Y. Chen and H. B. Zhu, "A dual- band strip- sleeve monopole antenna fed by CPW," Microwave and Optical Technology Letters, vol. 42, no. 1, pp. 70-72, 2004.

[20] S. C. Basaran and K. Sertel, "Dual- band frequency- reconfigurable monopole antenna for WLAN applications," Microwave and Optical Technology Letters, vol. 57, no. 1, pp. 55-58, 2015.

[21] R. S. Kshetrimayum, "Printed monopole antennas for multiband applications," International Journal of Microwave and Optical Technology, vol. 3, no. 4, pp. 474-480, 2008.

[22] M. Moosazadeh and S. Kharkovsky, "Compact and Small Planar Monopole Antenna With Symmetrical L- and U-Shaped Slots for WLAN/WiMAX Applications," in IEEE Antennas and Wireless Propagation Letters, vol. 13, pp. 388-391, 2014.

[23] M. Rizwan, M. Ali B. Abbasi, I. Saleem, S. M. Abbas and K Shehzad, "Review of Multiband Monopole Microstrip Patch Antenna for WiMAX Applications," In Proceedings of the International Conference on Advance Modeling and Simulation, Rawalpindi, pp. 149-153, 2011.

[24] R. Rengasamy and U. K. Kommuri, "A compact ACS-fed mirrored L-shaped monopole antenna with SRR loaded for multiband operation," Progress In Electromagnetics Research, vol. 16, pp. 159-167, 2016.

[25] N. O. Parchin, H. J. Basherlou, R. A. Abd-Alhameed and J. M. Noras, "Dual-band monopole antenna for RFID applications," Future Internet, vol. 11, no. 31, pp. 1-10, 2019.

\section{BIOGRAPHIES OF AUTHORS}

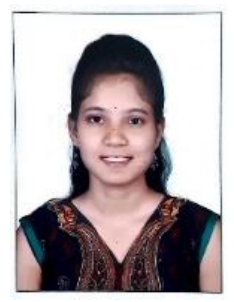

Spoorti Barigidad, received her B.Tech degree in electronics and communication engineering from Visvesvaraya Technological University in 2019. She is currently pursuing her master degree in digital electronics and communication engineering from Manipal Academy of Higher Education. Her interests are in antenna design for various applications.

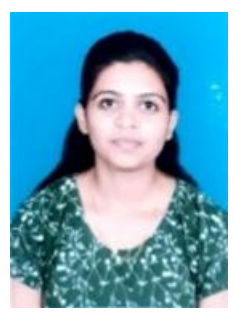

Aishwarya C. Yeshawant, received her B.Tech degree in electronics and communication engineering from Visvesvaraya Technological University in 2018. She is currently pursuing her master degree in digital electronics and communication engineering from Manipal Academy of Higher Education. Her interests are in antenna design for various applications.

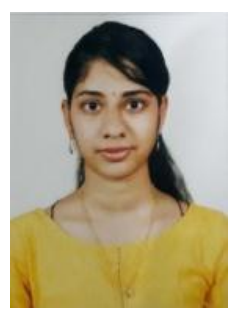

Sridevi Rao, received her B.Tech degree in electronics and communication engineering from Visvesvaraya Technological University in 2019. She is currently pursuing her Master degree in digital electronics and communication engineering from Manipal Academy of Higher Education. Her interests are in antenna design for various applications. 


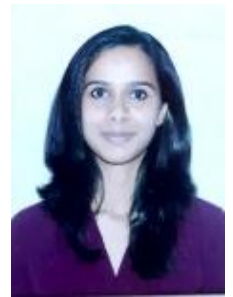

Tharunya C. A, received her B.Tech degree in electronics and communication engineering from the Visvesvaraya Technological University in 2019. She is currently pursuing her Master degree in digital electronics and communication engineering from Manipal Academy of Higher Education. Her interests are in antenna design for various applications.

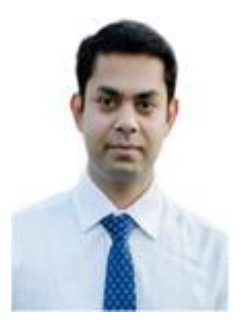

Tanweer Ali is working as assistant professor in the Department of Electronics and Communication Engineering at Manipal Instituteof Technology, Manipal Academy of Higher Education, Manipal, India. He is an active researcher in the field of microstrip antennas, wireless communication and microwave imaging. He has published more than 65 papers in reputed peer reviewed international journal and conferences. He is a senior member IEEE (SMIEEE), and associate member of IETE India. $\mathrm{He}$ is on the board of reviewers of journals like the IEEE Transactions on Antennas and Propagation, IEEE Antennas and Wireless Propagation Letters, IET Microwaves, Antennas \& Propagation, IET Electronics letter, Wireless Personal Communication (WPC), Springer, AEU-International Journal of Electronics and Communications, Microwave and optical Technology letters (MOTL), Wiley, International Journal of Antennas and Propagation, Hindawi, Advanced Electromagnetics, Progress in Electromagnetic Research (PIER), KSII Transaction of Engineering Science, Korea, International Journal of Microwave and Wireless Technologies, Frequenz, Radio engineering, etc. 